\title{
Computed tomography evaluation of rotary systems on the root canal transportation and centering ability
}

\author{
André PAGLIOSA(a) \\ Manoel Damião SOUSA-NETO(b) \\ Marco Aurélio VERSIANI(b) \\ Walter RAUCCI-NETO(a) \\ Yara Teresinha Corrêa \\ SILVA-SOUSA ${ }^{(a)}$ \\ Edson ALFREDO(a)
}

(a) Universidade de Ribeirão Preto - UNAERP, Faculty of Dentistry, Ribeirão Preto, SP, Brazil.

(b) Universidade de São Paulo - USP, School of Dentistry of Ribeirão Preto, Restorative Dentistry Department, Ribeirão Preto, SP, Brazil.

Declaration of Interests: The authors certify that they have no commercial or associative interest that represents a conflict of interest in connection with the manuscript.

Corresponding Author:

Yara Teresinha Corrêa Silva-Sousa

E-mail:ysousa@unaerp.br

DOI: 10.1590/1807-3107BOR-2015.vol29.0039

Submitted: Aug 22, 2014

Accepted for publication: Nov 09, 2014

Last revision: Jan 15, 2015

\begin{abstract}
The endodontic preparation of curved and narrow root canals is challenging, with a tendency for the prepared canal to deviate away from its natural axis. The aim of this study was to evaluate, by cone-beam computed tomography, the transportation and centering ability of curved mesiobuccal canals in maxillary molars after biomechanical preparation with different nickel-titanium (NiTi) rotary systems. Forty teeth with angles of curvature ranging from $20^{\circ}$ to $40^{\circ}$ and radii between $5.0 \mathrm{~mm}$ and $10.0 \mathrm{~mm}$ were selected and assigned into four groups $(n=10)$, according to the biomechanical preparative system used: Hero 642 (HR), Liberator (LB), ProTaper (PT), and Twisted File (TF). The specimens were inserted into an acrylic device and scanned with computed tomography prior to, and following, instrumentation at 3, 6 and $9 \mathrm{~mm}$ from the root apex. The canal degree of transportation and centering ability were calculated and analyzed using one-way ANOVA and Tukey's tests $(\alpha=0.05)$. The results demonstrated no significant difference $(p>0.05)$ in shaping ability among the rotary systems. The mean canal transportation was: $-0.049 \pm 0.083 \mathrm{~mm}(\mathrm{HR}) ;-0.004 \pm 0.044 \mathrm{~mm}(\mathrm{LB})$; $-0.003 \pm 0.064 \mathrm{~mm}(\mathrm{PT}) ;-0.021 \pm 0.064 \mathrm{~mm}(\mathrm{TF})$. The mean canal centering ability was: $-0.093 \pm 0.147 \mathrm{~mm}(\mathrm{HR}) ;-0.001 \pm 0.100 \mathrm{~mm}(\mathrm{LB})$; $-0.002 \pm 0.134 \mathrm{~mm}(\mathrm{PT}) ;-0.033 \pm 0.133 \mathrm{~mm}(\mathrm{TF})$. Also, there was no significant difference among the root segments $(p>0.05)$. It was concluded that the Hero 642, Liberator, ProTaper, and Twisted File rotary systems could be safely used in curved canal instrumentation, resulting in satisfactory preservation of the original canal shape.
\end{abstract}

Keywords: Endodontics; Cone-Beam Computed Tomography; Dental Instruments.

\section{Introduction}

The aim of endodontic treatment is to clean and shape root canals adequately so that canal disinfection and filling are optimized. According to Schilder, ${ }^{1}$ root canal preparation should present a flare shape from apical to coronal, preserving the apical foramen and not alter the original canal curvature. However, endodontic preparation in curved and narrow root canals is more challenging, with a tendency for the prepared canal to deviate away from its natural axis. ${ }^{2}$ 
In the last few decades the development of rotary nickel-titanium (NiTi) systems has significantly improved the quality of canal shaping and allowed for root canal preparation with continued rotation on narrow and/or curved root canals. ${ }^{3}$ The success of NiTi systems is related to the design, flexibility, and elastic memory. ${ }^{3,45}$ Moreover, NiTi instruments allow for greater conical canal preparation with less work time and more centered shaping of the canal in its original axis, producing rounder preparations and reducing procedural errors. ${ }^{4,6,7}$

Several studies have demonstrated successful results with continuous rotation full-sequence NiTi systems such as ProTaper, ${ }^{8,9}$ Hero $642,{ }^{10}$ Liberator ${ }^{5}$ and Twisted File. ${ }^{1,11}$ However, differences between the design and manufacturing procedures associated with these systems may result in variability in the final shape of the instrumented root canal. According to the Twisted File and ProTaper manufacturers, the use of greater tapers in combination with a "crown-down" preparation technique is intended to facilitate cleaning and shaping by shortening working time with the use of fewer instruments. ${ }^{6,12}$ In contrast, the Hero and Liberator systems allow for protocols that guarantee an enlargement in the apical diameter, even in curved root canals. ${ }^{13}$

Considering the clinical advantages of biomechanical preparation with rotary systems, it is necessary to investigate the shaping effectiveness of NiTi file systems and understand how the respective design features impact performance. Different methods can be used to evaluate the root canal shaping, though more recently, the use of computed tomography (CT) has been suggested for this purpose because it is a nondestructive and very precise method that even allows measuring the amount of root dentin removed by endodontic instruments. ${ }^{10}$ Therefore, the aim of this study was to evaluate, by volumetric cone beam computed tomography (CBCT), the degree of transportation and centering ability of curved mesiobuccal canals in maxillary molars after biomechanical preparation with different rotary nickel-titanium systems: Hero 642 (HR), Liberator (LB), Twisted File (TF), and ProTaper (PT).

\section{Methodology}

This study was approved by the Ethics Committee of Universidade de Ribeirão Preto - UNAERP, SP, Brazil (protocol \#097/2009).

\section{Specimen and root canal preparation}

Forty extracted human maxillary first molars were selected on the basis of having similar degrees of mesiobuccal canal curvature $\left(20^{\circ}-40^{\circ}\right)$ and radii (5-10 $\mathrm{mm})$, measured according to Schneider ${ }^{14}$ and Pruett et al..$^{15}$

Crowns were sectioned at the enamel-dentine junction in order to standardize root canal length $(17 \mathrm{~mm})$. Teeth were accessed by using an Endo-Access bur (Dentsply, Maillefer, Ballaigues, Switzerland) under air/water irrigation, and the root canal irrigated with $2.5 \% \mathrm{NaCL}$. Working length (WL) was established by inserting a $10 \mathrm{~K}$-file (Dentsply, Maillefer, Ballaigues, Switzerlan) to the root canal terminus and subtracting $1 \mathrm{~mm}$ from this measurement $(\mathrm{WL}=16 \mathrm{~mm})$.

Specimens were randomly divided into four groups $(n=10)$ according to the rotary system used: Twisted File (SybroEndo, Orange, USA), Hero (MicroMega, Besançon, France), Liberator (Miltex Inc., York, USA), and ProTaper (Dentsply Maillefer, Ballaigues, Switzerland).

A single operator performed the root canal instrumentation according to the manufacturers' instructions. In all groups, apical enlargement was performed with an instrument up to a file size of $20 \mathrm{~K}$ introduced at full WL. K-file manipulation included a three-quarter turn clockwise followed by a similar counter-clockwise movement and withdrawal. Upon removal, the instruments were cleaned. In the HR and LB groups, initially the coronal and middle third were shaped with EndoFlare (Micro-Mega, Besaçon, France) at $5 \mathrm{~mm}$ of the WL. Shaping continued to the full WL with HR and LB size 20 taper 0.02 , followed by $25,30,35$ and 40 . In the PT group, the shaping procedure commenced at $\mathrm{S} 1$ (at $7 \mathrm{~mm}$ of WL) and SX (at $5 \mathrm{~mm}$ of $\mathrm{WL}$ ) in order to prepare the coronal and middle third, respectively. The apical third was prepared with S1, S2, F1, and followed by F2 at full WL. In the TF group, the shaping procedure commenced with TF size 25 taper 0.08 to prepare the coronal third. TF size 25 taper 0.06 was 
used until $2 \mathrm{~mm}$ short of WL. Shaping continued to the full WL with TF size 25 taper 0.04 , followed by 0.06 and 0.08 . The irrigation was performed with $3 \mathrm{~mL}$ of $2.5 \%$ $\mathrm{NaCL}$ after each instrument. X-Smart torque control motor (Dentsply Maillefer, Ballaigues, Switzerland) was used to operate all files at $300 \mathrm{rpm}$ and $2.4 \mathrm{Ncm}$. Each instrument was used to prepare 5 canals, corresponding with a single use.

\section{Image analysis}

The specimens were positioned in an acrylic resin holder and scanned before and after instrumentation by using an i-CAT cone beam 3-D scanner (Dental Imaging System, Salt Lake City, USA). Exposure parameters were $120 \mathrm{kV}$ and $8 \mathrm{~mA}$. The field of view was $17 \mathrm{~cm}$ in diameter and $13 \mathrm{~cm}$ in height. Images slices were taken at 3,6 , and $9 \mathrm{~mm}$ short of the apical foramen, corresponding to the apical, middle, and coronal thirds, respectively.

The images were analyzed using CorelDraw X3 software (Corel Corporation, Ottawa, Canada), where the central axis prior to, and following, root canal instrumentation was marked with the convergence of four dotted lines drawn in the vestibular-palatine direction (with a gap of $45^{\circ}$ between them). For canal transportation and centering ability analysis, nine different measures were made: $d 1, d 2, d 3, m 1$, $\mathrm{m} 2, \mathrm{~m} 3, \mathrm{D} 1, \mathrm{D} 2$, and D3. The $\mathrm{d} 1, \mathrm{~d} 2$, and $\mathrm{d} 3$ values correspond to the difference between the distances of the distal periphery prior to, and following, root canal instrumentation. Similarly, the $\mathrm{m} 1, \mathrm{~m} 2$, and $\mathrm{m} 3$ values correspond to the difference between the distances of the mesial periphery prior to, and following, root canal instrumentation. D1, D2, and D3 correspond to the final diameter after root canal instrumentation. The image analysis and measurement procedure are represented in Figure 1.

\section{Canal transportation}

Canal transportation corresponded to the shortest distances from the central axis of the canal to the periphery before and after instrumentation, and was measured in mesial and distal directions. Canal transportation (CT) was calculated according to the formula of Loizides et al. ${ }^{6} \mathrm{CT}=\mathrm{MT}$ - DT, where MT represents the mesial transportation distance and DT represents the distal transportation distance. MT was determined by the mean of the $\mathrm{m} 1, \mathrm{~m} 2$, and $\mathrm{m} 3$ values. Similarly, DT was determined by the mean of the d1, d2, and $\mathrm{d} 3$ values. In relation to the transportation direction, a negative value represents transportation occurring in the direction facing the furcation (i.e., distal direction), whereas positive values represent transportation lateral to the curvature (i.e., mesial direction), and a " 0 " value indicates no canal transportation.

\section{Centering ability}

Centering ability corresponded to the ability of the instrumented molars to stay centered in the original canal axis. Centering (CA) was calculated for each section according to the formula of Loizides et al.: 6 $\mathrm{CA}=$ ( $\mathrm{m}$ total $-\mathrm{d}$ total $) / \mathrm{CD}$, where $\mathrm{CD}$ (canal diameter) was determined by the mean of D1, D2, and D3.

\section{Statistical analysis}

Data resulting from canal transportation and centering ability were submitted to one-way ANOVA and Tukey's tests. Statistical analysis was performed with Statistical Package for the Social Science (SPSS) 17.0 (SPSS Inc., Chicago, USA).

\section{Results \\ Canal transportation}

The canal transportation $(\mathrm{mm})$ mean and standard deviation among the three tested levels in each group are displayed in Table 1.

There was no significant difference between the four systems concerning canal curvature changes after instrumentation at all root section levels. Comparing the transportation percentage, $114(95 \%)$ canal deviations occurred in 120 of the measurements performed, with only $6(5 \%)$ not presenting any deviation. The PT presented with more specimens with no deviation, followed by HR and TF. All four groups had less transported canals toward the outside of the curve (mesial), and most canals were transported toward the inside of the curve (distal) on the apical $3 \mathrm{~mm}$ sections. The HR group had the highest degree of distal transportation while the PT/LB groups had the lowest. Table 2 describes the canal transportation direction among the studied groups. 
Table 1. Mean of canal transportation $(\mathrm{mm})$ and standard deviation among the groups and root section levels.

\begin{tabular}{lccccc}
\hline Root section levels & $\begin{array}{c}\text { HR } \\
\text { Hero 642 }\end{array}$ & $\begin{array}{c}\text { LB } \\
\text { Liberator }\end{array}$ & $\begin{array}{c}\text { PT } \\
\text { ProTaper }\end{array}$ & TF & Twisted File \\
$3 \mathrm{~mm}$ & $-0.103 \pm 0.102$ & $-0.034 \pm 0.035$ & $-0.019 \pm 0.085$ & $-0.047 \pm 0.078$ & 0.114 \\
$6 \mathrm{~mm}$ & $-0.031 \pm 0.072$ & $0.004 \pm 0.044$ & $-0.013 \pm 0.051$ & $-0.023 \pm 0.049$ & 0.526 \\
$9 \mathrm{~mm}$ & $-0.014 \pm 0.039$ & $0.018 \pm 0.037$ & $0.025 \pm 0.044$ & $0.007 \pm 0.057$ & 0.243
\end{tabular}

*ANOVA $(p<0.05)$. $\left({ }^{*}\right)$ Positive values indicate mesial direction of transportation. Negative values indicate distal direction of transportation.

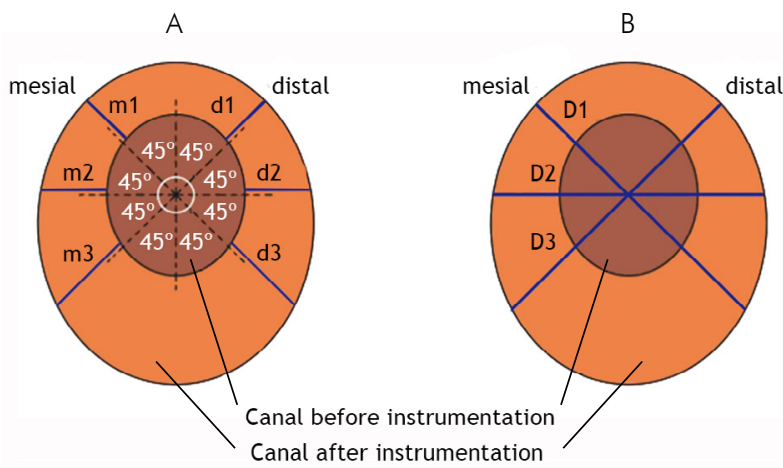

Figure 1. Schematic of the super-positioned root canals, before and after instrumentation, with central axis and respective peripheral distances. (A) Difference between the distances of the distal portion $\mathrm{d} 1, \mathrm{~d} 2$ and $\mathrm{d} 3$; difference between the distances of the mesial portion $\mathrm{m} 1, \mathrm{~m} 2$ and $\mathrm{m} 3$. (B) Final diameter of the root canal after instrumentation D1, D2 and D3.

Table 2. Canal transportation direction among groups.

\begin{tabular}{lccc}
\hline Group & Mesial & Distal & No deviation \\
HR-Hero 642 & 8 & 20 & 2 \\
LB-Liberator & 14 & 16 & 0 \\
PT-ProTaper & 11 & 16 & 3 \\
TF-Twisted File & 10 & 19 & 1 \\
\hline
\end{tabular}

\section{Centering ratio}

The centering ability $(\mathrm{mm})$ mean and standard deviation among the three tested levels in each group are displayed in Table 3 . The results revealed no significant difference between the four systems concerning centering ability after instrumentation at all root section levels.

\section{Discussion}

Considering the development of different devices and instrumentation techniques to perform root canal preparation, several methods have been proposed to evaluate the shaping ability of instrumented canals with the aim of preserving the apical foramen and original canal curvature. ${ }^{5,8,13,16,17,18,19}$ Satisfactory results have been obtained with the root serial section technique, ${ }^{16}$ radiographic platform, ${ }^{18}$ and root resin canal simulation. ${ }^{17}$ However, more accurate information can be achieved with micro-computed tomography (micro-CT) $)^{6,13}$ and computed tomography $(\mathrm{CT}),{ }^{1,7,8,20}$ which allows for the quantitative and qualitative evaluation of root canals in 3 dimensions. ${ }^{9}$ Therefore, in the present study, the root canal transportation and centering ability of four different NiTi rotary systems were evaluated with CT.

Table 3. Mean of centering ability $(\mathrm{mm})$ and standard deviation among the groups and root section levels.

\begin{tabular}{lccccc}
\hline Root section levels & $\begin{array}{c}\text { HR } \\
\text { Hero } 642\end{array}$ & $\begin{array}{c}\text { LB } \\
\text { Liberator }\end{array}$ & $\begin{array}{c}\text { PT } \\
\text { ProTaper }\end{array}$ & TF & P \\
$3 \mathrm{~mm}$ & $-0.165 \pm 0.156$ & $-0.064 \pm 0.069$ & $-0,045 \pm 0.135$ & $-0.065 \pm 0.135$ & 0.169 \\
$6 \mathrm{~mm}$ & $-0.066 \pm 0.158$ & $0.013 \pm 0.097$ & $-0.031 \pm 0.131$ & $-0.055 \pm 0.117$ & 0.527 \\
$9 \mathrm{~mm}$ & $-0.046 \pm 0.105$ & $0.050 \pm 0.103$ & $0.069 \pm 0.116$ & $0.021 \pm 0.139$ & 0.151 \\
\hline
\end{tabular}

*ANOVA $\left.(p<0.05) .{ }^{*}\right)$ Positive values indicate mesial direction of transportation. Negative values indicate distal direction of transportation. 
Previous reports already clarify that canal transportation can be considered a procedural error resulting in lower efficiency of preparation techniques due to inadequate root canal cleaning and the persistency of periapical lesions. ${ }^{21}$ In this sense, $\mathrm{Wu}$ et al. ${ }^{22}$ reported that apical transportation of more than $0.3 \mathrm{~mm}$ could negatively affect the sealability of filling material. In the present study the shaping ability of all groups was similar, considering the apical transportation and centering ability values in which none of the rotary systems used reached apical transportation greater than $0.2 \mathrm{~mm}$. These results corroborate with previous reports that show minimal rates of apical deviation of narrow and curved canals instrumented with NiTi rotary systems. . $^{1,58}$

Although in the present study there was no statistical difference between the NiTi systems used, the data analysis shows a centralization tendency and lower transportation values for PT and TF. These results are probably related to the minimal interaction of these instruments in the apical region, whereby the anatomical diameter was established with a size 20 file and the final diameter related to a size 25 file. It is important to consider that this final diameter determination of PT and TF is based on orientation provided by the respective manufacturers. Similar results and conclusions were achieved by Versiani et al., ${ }^{8}$ which reported favorable centering ability and canal transportation results even with a final file with a size 30 diameter.

Similarly, satisfactory canal transportation and centering ability results of a TF system compared to different grinded NiTi files were previously reported. ${ }^{1,711}$ The shaping ability of these instruments could be related to the difference in manufacturing method, which consists of twisting the metal and special surface conditioning to provide increased flexibility and fracture resistance ${ }^{23}$ Gergi et al. ${ }^{7}$ and Marzouk and Ghoneim ${ }^{2}$ also reported that using 0.08 taper of TF to full WL did not result in any severe aberrations in the apical portion. Therefore, according to Marzouk and Ghoneim, ${ }^{2}$ the improved results of canal transportation with TF compared to single file reciprocating systems may be due to using lower tapered files prior to using a 0.08 tapered file.
A previous study also reported an improved centering ratio with Hero 642 compared to stainless K-files. ${ }^{24}$ Also, satisfactory results were observed when the original curvature deviation with Hero 642 instrumented canals was compared to other NiTi rotary systems. ${ }^{10}$ These results corroborate the present study as satisfactory centering ability results were observed with the Hero 642 system among all root canal segments.

Another relevant parameter to be analyzed is related to the deviation directions according to the root canal segments and instrument type/ kinematics. ${ }^{9,25}$ In the present study, we observed a greater incidence of distal deviations (inside of the curve) on all systems used. This result differs from previous studies that indicate that the apical segment usually has more canal transportation toward the outside of the curve. ${ }^{19,22,25}$ As in the present study, an average deviation from the direction of the different thirds was used, and hence our results probably reflect the higher incidence of deviation inside of the curve that occurs in the cervical and middle segments, as previously reported by Stavileci et al. ${ }^{9}$

An important difference between the NiTi systems used in the present study is related to the number of the files used. ProTaper and Twisted File systems use a small number of files in an attempt to simplify the root canal instrumentation, whereas Hero and Liberator systems allow the use of a larger number of instruments. Since the anatomic diameter at $1 \mathrm{~mm}$ from the apex of the mesiobuccal root is around $0.22 \mathrm{~mm}$ and $0.43 \mathrm{~mm}$ in mesial-distal and buccal-lingual directions, respectively, ${ }^{22}$ Hero and Liberator systems provide further enlargement in the third apical dentine removal, which is greater in this region compared to the final instrument of the ProTaper and Twisted File. Although Hero and Liberator instrumentation results in a larger apical diameter, the transportation values obtained with these instruments were similar to those obtained with the ProTaper and Twisted File systems. Corroborating these results, Pasternak-Júnior et al. ${ }^{20}$ observed that the final instrument \#45 did not cause deviation when compared to instrument \#35. The tendency to centralization, and consequently the low transport values, obtained in this study with the Hero and 
Liberator systems are probably related to the use of. 02 taper instruments in the apical segment, and even with larger diameters provide safety in the preparation of curved root canals due to the flexibility of these instruments. ${ }^{20}$

Despite the similar centering ability between the four rotary systems tested in this study, the use of a size \#40 final instrument in Hero and Liberator systems suggests that the removal of dentin in the cervical segment was around $100-150 \mu \mathrm{m}$. Contrary to this, the ProTaper and Twisted File systems probably made less contact with the dentin walls in the apical region, as the final instrument was a \#25 size file. The removal of the apical dentin during biomechanical preparation plays an important role in the cleaning and disinfection of the root canal system. According to Berber $e$ al. ${ }^{26}$ the microorganisms inside the root canal are able to penetrate the dentinal tubules at around 200 micrometers. Regarding the impact of instrumentation cleaning, Fornari et al. ${ }^{27}$ observed that the larger the final diameter, the greater the percentage of touched walls, which leads to increased cleaning of the root

\section{References}

1. Schilder H. Cleaning and shaping the root canal. Dent Clin North Am. 1974 Apr;18(2):269-96.

2. Marzouk AM, Ghoneim AG. Computed tomographic evaluation of canal shape instrumented by different kinematics rotary nickel-titanium systems. J Endod. 2013 Jul;39(7):906-9.

3. Jodway B, Hulsmann MA. A comparative study of root canal preparation with NiTi-TEE and $\mathrm{K} 3$ rotary Ni-Ti instruments. Int Endod J. 2006 Jan;39(1):71-80.

4. Kim HC, Yum J, Hur B, Cheung GS. Cyclic fatigue and fracture characteristics of ground and twisted nickel-titanium rotary files. J Endod. 2010 Jan;36(1):147-52.

5. Stewart JT, Lafkowitz S, Appelbaum K, Hartwell G. Distortion and breakage of Liberator, EndoSequence, and ProFile systems in severely curved roots of molars. J Endod. 2010 Apr;36(4):729-31.

6. Loizides AL, Kakavetsos VD, Tzanetakis GN. A comparative study of the effects of two nickel-titanium preparation techniques on root canal geometry assessed by microcomputed tomography. J Endod. 2007 Dec;33(12):1455-9.

7. Gergi R, Rjeily JA, Sader J, Naaman A. Comparison of canal transportation and centering ability of twisted files, Pathfile-ProTaper System, and stainless steel hand K-files by using computed tomography. J Endod. 2010 May;36(5):904-7. canal. Aside from this, the enlargement of the apical segment favors the effectiveness of substances used during both the root canal irrigation as medications in certain periapical pathological conditions. ${ }^{26,27}$

In light of the recent efforts to simplify the biomechanical preparation techniques, the effect of rotary instruments at the apical segment should be considered for the proper cleaning, shaping, and disinfection of root canals. Thus, in systems like the Twisted File and ProTaper, which favor the preparation of cervical and middle segments through the use of instruments with greater taper, additional smaller taper files could be considered to complement this technique and enlarge the apical region.

\section{Conclusion}

Within the experimental conditions and results of the present study, it could be concluded that Hero 642, Liberator, ProTaper, and Twisted File systems can be safely used in curved canals instrumentation at full working length with satisfactory preservation of the original canal shape.

8. Versiani MA, Pascon EA, Souza CJ, Borges MA, SousaNeto MD. Influence of shaft design on the shaping ability of 3 nickel-titanium rotary systems by means of spiral computerized tomography. Oral Surg Oral Med Oral Pathol Oral Radiol Endod. 2008 Jun;105(6):807-13.

9. Stavileci M, Hoxha V, Görduysus Ö, Tatar I, Laperre K, Hostens J, et al. Effects of preparation techniques on root canal shaping assessed by micro-computed tomography. Med Sci Monit Basic Res. 2013 Jun 13;19:163-8.

10. Elsherief SM, Zayet MK, Hamouda IM. Cone-beam computed tomography analysis of curved root canals after mechanical preparation with three nickel-titanium rotary instruments. J Biomed Res. 2013 Jun;27(4):326-35.

11. Hashem AA, Ghoneim AG, Lutfy RA, Foda MY, Omar GA. Geometric analysis of root canals prepared by four rotary NiTi shaping systems. J Endod. 2012 Jul;38(7):996-1000.

12. Larsen CM, Watanabe I, Glickman GN, He J. Cyclic fatigue analysis of a new generation of nickel titanium rotary instruments. J Endod. 2009 Mar;35(3):401-3.

13. Bergmans L, Van Cleynenbreugel J, Wevers M, Lambrechts P. A methodology for quantitative evaluation of root canal instrumentation using microcomputed tomography. Int Endod J. 2001 Jul;34(5):390-8. 
14. Schneider SW. A comparison of canal preparations in straight and curved root canals. Oral Surg Oral Med Oral Pathol. 1971 Aug;32(2):271-5.

15. Pruett JP, Clement DJ, Carnes DL Jr. Cyclic fatigue testing of nickel-titanium endodontic instruments. J Endod. 1997 Feb;23(2):77-85.

16. Garala M, Kuttler S, Hardigan P, Steiner-Carmi R, Dorn S. A comparison of the minimum canal wall thickness remaining following preparation using two nickel-titanium rotary systems. Int Endod J. 2003 Sep;36(9):636-42.

17. Rangel S, Cremonese R, Bryant S, Dummer P. Shaping ability of RaCe rotary nickel-titanium instruments in simulated root canals. J Endod. 2005 Jun;31(6):460-3.

18. Javaheri HH, Javaheri GH. A comparison of three NiTi rotary instruments in apical transportation. J Endod. 2007 Mar;33(3):284-6.

19. Silva e Souza PA, Dores RS, Tartari T, Pinheiro TP, Tuji FM, Silva e Souza Jr MH. Effects of sodium hypochlorite associated with EDTA and etidronate on apical root transportation. Int Endod J. 2014 Jan;47(1):20-5.

20. Pasternak-Júnior B, Sousa-Neto MD, Silva RG. Canal transportation and centring ability of RaCe rotary instruments. Int Endod J. 2009 Jun;42(6):499-506.

21. Paqué F, Musch U, Hulsmann M. Comparison of root canal preparation using $\mathrm{RaCe}$ and ProTaper rotary Ni-Ti instruments. Int Endod J. 2005 Jan;38(1):8-16.
22. Wu MK, R'oris A, Barkis D, Wesselink PR. Prevalence and extent of long oval canals in the apical third. Oral Surg Oral Med Oral Pathol Oral Radiol Endod. 2000 Jun;89(6):739-43.

23. Hou X, Yahata Y, Hayashi Y, Ebihara A, Hanawa T, Suda H. Phase transformation behavior and bending property of twisted nickel-titanium endodontic instruments. Int Endod J. 2011 Mar;44(3):253-8.

24. Thompson SA, Dummer PMH. Shaping ability of Hero 642 rotary nickel-titanium instruments in simulated root canals: Part 1. Int Endod J. 2000 May;33(3):248-54.

25. Hartmann MS, Fontanella VR, Vanni JR, Fornari VJ, Barletta FB. CT evaluation of apical canal transportation associated with stainless steel hand files, oscillatory technique and pro taper rotary system. Braz Dent J. 2011;22(4):288-93.

26. Berber VB, Gomes BPFA, Sena NT, Vianna ME, Ferraz CCR, Zaia AA, Souza-Filho FJ. Efficacy of various concentrations of $\mathrm{NaOCl}$ and instrumentation techniques in reducing Enterococcus faecalis within root canals and dentinal tubules. Int Endod J. 2006 Jan;39(1):10-7.

27. Fornari VJ, Silva-Sousa YTC, Vanni JR, Pécora JD, Versiani MA, Sousa-Neto MD. Histological evaluation of the effectiveness of increased apical enlargement for cleaning the apical third of curved canals. Int Endod J. 2010 Nov;43(11):988-94. 